\title{
Effects of the 2003 advertising/promotion ban in the United Kingdom on awareness of tobacco marketing: findings from the International Tobacco Control (ITC) Four Country Survey
}

\author{
F Harris, A M Mackintosh, S Anderson, G Hastings, R Borland, G T Fong, D Hammond, \\ $K M$ Cummings for the ITC Collaboration
}

Tobacco Control 2006;15(Suppl III):iii26-iii33. doi: 10.1136/tc.2005.013110

Background: In February 2003, a comprehensive ban on tobacco promotion came into effect in the United Kingdom, which prohibited tobacco marketing through print and broadcast media, billboards, the internet, direct mail, product placement, promotions, free gifts, coupons and sponsorships.

Objective: To investigate the impact of the UK's comprehensive ban on tobacco promotion on adult smokers' awareness of tobacco marketing in the UK relative to Canada, the United States and Australia. Design: A total of 6762 adult smokers participated in two waves of a random digit dialled telephone survey across the four countries. Wave 1 was conducted before the UK ban (October-December 2002) and Wave 2 was conducted after the UK ban (May-September 2003).

See end of article for authors' affiliations Key measures: Awareness of a range of forms of tobacco marketing.

Results: Levels of tobacco promotion awareness declined significantly among smokers in the UK after implementation of the advertising ban. Declines in awareness were greater in those channels regulated by the new law and change in awareness of tobacco promotions was much greater in the UK than the other three countries not affected by the ban. At least in the short term, there was no evidence that the law resulted in greater exposure to tobacco promotions in the few media channels not covered by the law. Notwithstanding the apparent success of the UK advertising ban and the controls in other countries, 9-22\% of smokers in the four countries still reported noticing things that promoted smoking "often or very often" at Wave 2.

Conclusions: The UK policy to ban tobacco advertising and promotion has significantly reduced exposure to pro-tobacco marketing influences. These findings support the effectiveness of comprehensive bans on advertising and promotion, as included in the Framework Convention on Tobacco Control.

Received 23 June 2005 Accepted 29 November 2005

Professor Gerard Hastings, Institute for Social

Marketing, University of Stirling, Stirling, FK9 4LA UK; gerard.hastings@stir. ac.uk
$\mathrm{T}$ bacco advertising has been reported to increase tobacco consumption. ${ }^{1-3}$ Recent research has also shown that awareness and participation in other forms of tobacco promotion are associated with smoking status. ${ }^{4}$ Furthermore, young people's future smoking behaviour has been shown to be predicted by their awareness and involvement in tobacco advertising, sponsorship and merchandising. ${ }^{5}$

Policymakers have responded to the public health threat posed by tobacco marketing by introducing regulatory policies to control the industry's advertising and promotional activities. In particular, the Framework Convention on Tobacco Control (FCTC) calls for comprehensive bans on such activities. ${ }^{6}$ Previous research suggests that comprehensive advertising and promotion bans can reduce tobacco consumption, whereas partial bans have little or no effect. ${ }^{3}$ Despite this evidence, many governments have been reluctant to implement comprehensive advertising bans. Indeed, the strength of advertising and promotion restrictions varies considerably across countries. ${ }^{6-10}$

In February 2003, the United Kingdom joined countries such as Canada, Australia, and New Zealand when a comprehensive ban on tobacco promotion came into effect. The UK Tobacco Advertising and Promotion Act was extremely comprehensive, outlawing any published material that has the "purpose" or "effect" of promoting tobacco. Specifically, it prohibits tobacco marketing through print and broadcast media, billboards, the internet, direct mail, product placement, promotions, free gifts, coupons and sponsorships. ${ }^{11}$ It also introduced transitional regulation on point of sale, brand-sharing and sponsorship, whereby the regulations provided for certain time limited exceptions to the prohibition of these channels. Certain sections of the act did not come into effect for point of sale until 21 December 2004 and for brand-sharing and sponsorship until 31 July 2005.

The current study sought to evaluate the comprehensive restrictions introduced in the UK, by comparing measures of exposure among UK smokers with those from Canada, the United States, and Australia. The depth and breadth of restrictions on advertising and promotion vary considerably among these other countries.

In Australia, the Tobacco Advertising Prohibition (TAP) Act 1992 made most forms of tobacco marketing illegal, with only a few limited exceptions, such as price promotion. ${ }^{9}$ The following forms of tobacco marketing are partially regulated: point of sale (store) advertising, free samples, gifts/discounts - all of which vary by state-and arts sponsorship, for which acknowledgement of assistance and support is still permitted. Sporting sponsorships are banned, but exemptions are allowed until 2006 for internationally significant events, most notably Formula One (F1) motor racing. The Act allows incidental and accidental publishing of what would otherwise be tobacco advertising, which explains the existence of pictures of Fl cars with cigarette brands and logos in the Australian print and broadcast media.

Abbreviations: CATI, computer-assisted telephone interview; FCTC, Framework Convention on Tobacco Control; GLM, general linear model; ITC-4, International Tobacco Control Four Country Survey 
In Canada, the Tobacco Act (1997) bans the use of testimonials and endorsements, lifestyle advertisements (which evoke an image or emotion about a way of life that includes glamour, recreation, excitement, vitality, risk or daring), television and radio broadcasts, gifts, bonuses, premium, cash rebates, games, lotteries and contests. ${ }^{10}$ The Act also restricts informational advertisements (that provide factual information) to publications with a minimum adult readership of $85 \%$ and addressed to identifiable named adults and signs in places where young persons are not permitted. Sponsorship and promotion of accessories that display a tobacco product-related brand element were restricted in October 2003.

The USA has the fewest restrictions on tobacco marketing among the four countries in the study. Broadcast advertising of tobacco has been banned since January 1971. The Tobacco Master Settlement Agreement (1998) prohibits youth targeting, use of cartoons, naming rights for stadiums or arenas, outdoor advertising and transit advertisements, and tobacco brand name merchandise. ${ }^{12}$ It also places restrictions on sponsorships (only one brand name sponsorship per year is permitted and sponsoring of teams and leagues are prohibited), store advertisements (advertising outside retail establishments is limited to 14 square feet) and product placement, free samples and gifts (restrictions to prevent access by a youth audience). However, many marketing channels remain open, including: advertisements in newspapers/magazines, email and mobile phone messages, direct mail, competitions, internet sites, leaflets and signs outside bars, pubs and clubs. Table 1 shows the comparative levels of tobacco marketing regulation in the UK, Canada, the USA, and Australia in 2002 and 2003 at Wave 1 (OctoberDecember 2002) and Wave 2 (May-September 2003). As table 1 indicates, between 2002 and 2003, the UK changed from having the fewest restrictions to having the most comprehensive restrictions on tobacco marketing, similar to Australia's restrictions.

We evaluated the impact of the UK advertising ban using data from Waves 1 and 2 of the International Tobacco Control Four Country Survey (ITC-4), a cohort of over 8000 adult smokers across four countries: Canada, the United States, the United Kingdom, and Australia. The UK ban was introduced in February 2003, between the two waves. Both survey waves asked respondents about their exposure to pro-tobacco marketing influences. Thus, ITC-4 allows comparisons within
UK smokers before and after the ban, as well as comparisons between UK smokers and those from the three countries not affected by the ban: Canada, the USA, and Australia.

This study addresses three questions: (1) How do adult smokers in the four countries differ at baseline and over time in exposure to tobacco marketing? (2) What was the impact of the UK ban on smokers' overall awareness of tobacco marketing and their awareness of the specific forms of marketing prohibited under the ban? (3) Was there evidence that the UK ban led to a shift in tobacco product marketing to channels unaffected by the ban?

\section{METHOD}

\section{Participants}

Participants were adult ( 18 years of age or more) smokers (defined as having smoked at least 100 cigarettes in their lifetime and who currently smoked at least once a month) who agreed to be interviewed as part of ITC-4. The samples were broadly representative of their parent populations.

ITC-4 is an annual cohort survey. The first wave was conducted between October and December 2002 and the second wave between May and September 2003. The survey field work was conducted using computer assisted telephone interview (CATI) by two research firms: Roy Morgan Research (Melbourne) for Australia and the UK, and Environics Research Group (Toronto) for the USA and Canada. The survey was conducted in English, or in French if desired in the francophone areas of Canada. Strict protocols were developed and implemented to ensure equivalence of methods across the two companies and between the two languages. Using a stratified random-digit dialling technique, households were contacted and screened for adult smokers with the next birthday who would agree to participate in the study. Those who agreed were rescheduled for a 35-minute telephone survey a week later, and were sent a cheque or voucher to compensate for their time. No substitution of respondents within a household was permitted unless it was known that the selected respondent would be absent for the entire duration of the fieldwork procedure. Additional detail about the methods can be found in Thompson et al. ${ }^{13}$

Respondents lost to attrition are replenished at each wave of the ITC-4 using the same recruitment protocols as at Wave 1. Unless indicated otherwise, findings are reported for the cohort participants (those who responded to both Waves 1 and 2) only.

Table 1 Comparison of the levels of tobacco marketing regulation across the four countries

\begin{tabular}{|c|c|c|c|c|c|c|c|c|c|}
\hline & & \multicolumn{2}{|l|}{ Canada } & \multicolumn{2}{|l|}{ USA } & \multicolumn{2}{|l|}{ Australia } & \multicolumn{2}{|l|}{ UK } \\
\hline & & Wave 1 & Wave 2 & Wave 1 & Wave 2 & Wave 1 & Wave 2 & Wave 1 & Wave 2 \\
\hline \multirow[t]{6}{*}{ Advertising } & TV & $\mathrm{X}$ & $\mathrm{X}$ & $x$ & $x$ & $x$ & $\mathbf{x}$ & $x$ & $\mathrm{x}$ \\
\hline & Radio & $\mathrm{X}$ & $x$ & $\mathrm{x}$ & $\mathrm{x}$ & $\mathrm{x}$ & $\mathrm{X}$ & 0 & $\mathrm{X}$ \\
\hline & Movie & 0 & 0 & - & - & $x$ & $x$ & $x$ & $\mathrm{x}$ \\
\hline & Billboards & $x$ & $\mathbf{x}$ & $x$ & $\mathbf{x}$ & $\mathrm{x}$ & $\mathrm{X}$ & 0 & $x$ \\
\hline & Newspapers/mags & 0 & 0 & - & - & $x$ & $x$ & - & $x$ \\
\hline & Store & $x$ & $\mathbf{X}$ & 0 & 0 & 0 & 0 & - & - \\
\hline \multirow[t]{2}{*}{ Sponsorship } & Sports & - & - & 0 & 0 & 0 & 0 & - & - \\
\hline & Arts & - & - & 0 & 0 & 0 & 0 & - & - \\
\hline \multirow[t]{11}{*}{ Promotions } & Free samples & $\mathbf{x}$ & $\mathbf{x}$ & 0 & 0 & 0 & 0 & - & $\mathbf{x}$ \\
\hline & Special price & - & - & 0 & 0 & - & - & - & $\mathbf{x}$ \\
\hline & Gift/discount & $\mathrm{X}$ & $x$ & 0 & 0 & 0 & 0 & - & $\mathrm{X}$ \\
\hline & Email & 0 & 0 & - & - & $\mathbf{x}$ & $x$ & - & $\mathbf{x}$ \\
\hline & Mobile phone & 0 & 0 & - & - & $x$ & $\mathrm{x}$ & - & $x$ \\
\hline & Direct mail & 0 & 0 & - & - & 0 & 0 & - & 0 \\
\hline & Branded clothing & 0 & 0 & $x$ & $x$ & $x$ & $\mathrm{X}$ & - & - \\
\hline & Competitions & 0 & 0 & - & - & $\hat{x}$ & $x$ & - & $\mathbf{x}$ \\
\hline & Internet sites & - & - & - & - & $\mathrm{X}$ & $\mathbf{x}$ & 0 & $\mathrm{X}$ \\
\hline & Leaflets & 0 & 0 & - & - & $\mathrm{x}$ & $\mathrm{X}$ & - & $\mathrm{x}$ \\
\hline & Signs & 0 & 0 & - & - & $\mathrm{x}$ & $\mathrm{x}$ & - & - \\
\hline
\end{tabular}




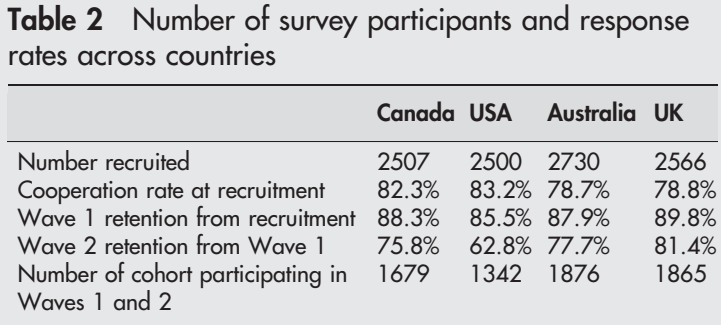

A total of 6762 adult smokers participated in both Waves 1 and 2 of the survey. Table 2 details the number of participants in each country and the response rates for the recruitment and Wave 1 and Wave 2 surveys. The study protocol was cleared for ethics by the institutional review boards or research ethics boards in each of the countries: the University of Waterloo (Canada), Roswell Park Cancer Institute (USA), the University of Illinois-Chicago (USA), the University of Strathclyde (UK), and The Cancer Council Victoria (Australia)

\section{Measures \\ Overall awareness of tobacco marketing}

Three measures were used to assess overall awareness of tobacco marketing. First, salience of pro smoking was assessed by asking: "Thinking about everything that happens around you. In the last six months, how often have you noticed things that promote smoking?" Participants were asked to give their answer in terms of one of the following five options: 1, never; 2, rarely; 3, sometimes; 4, often; 5, very often. Second, the number of channels through which participants had noticed tobacco marketing was calculated by counting the number of positive responses for each of the individual advertising, sponsorship, and promotional channels, described below (up to a maximum of 20, 19 of which are listed in table 3 and the 20th was awareness of adverts elsewhere). Finally, a derived promotions variable, awareness of any form of tobacco promotion, was computed by assigning a code 1 if participants had noticed any of the 11 promotions listed in table 3 and, if not, a code 0 was assigned.

Awareness of tobacco marketing: specific channels Categorical data were collected about awareness of three types of tobacco marketing: (1) advertising; (2) sponsorship (sports and arts); and (3) promotions. For advertising participants were asked whether in the previous six months they had noticed cigarettes or tobacco products being advertised in each of the following places: television, radio, movie, billboards, newspapers/magazines and store. For sponsorship, participants were asked whether in the previous six months they had seen or heard about, first of all, any sport or sporting event sponsored by or connected with (a) brands of cigarettes and (b) tobacco companies; and second any music, theatre, art or fashion events sponsored by or connected with (a) brands of cigarettes and (b) tobacco companies. A combined variable, awareness of sports or arts sponsorship was computed for the purpose of analysis. For promotions participants were asked whether in the previous six months they had noticed each of the following types of tobacco promotion: free samples, special price, gifts/discounts, email messages, mobile phone messages, direct mail, branded clothing or other non-tobacco products, competitions, internet sites, leaflets and signs in bars, pubs or clubs. In each case, participants were asked to respond "yes" (coded 1) or "no" (coded 0) (respondents who answered "don't know" were also coded 0 ).
Demographics and smoking behaviour

The survey included validated measures of smoking behaviour and quit history. A continuous measure of cigarette consumption was measured as the reported number of cigarettes smoked per day. Cigarette consumption for smokers who smoked weekly or monthly was converted to a daily consumption figure by dividing the number of cigarettes smoked weekly by seven or dividing the number of cigarettes smoked monthly by 30.4. Respondents also reported whether they had "ever" tried to quit smoking and the number of prior quit attempts. Level of education consisted of three categories: high school diploma or lower; technical, trade school, community college, or some university; and university degree. Annual income was categorised into "under \$30 000" (low), "\$30 000-\$59 999" (moderate), and "\$60 000 and over" (high) for the USA, Canadian, and Australian samples. For the UK sample, we used the following categories: "£15 000 or under" (low), “£15 001-£30 000," (moderate) and "£30 001 and over" (high). Income is a relative measure, benchmarked to each country, owing to the difficulties in equating income. It was therefore categorised as low, moderate or high in each country relative to other incomes in the same country. Identified minority status was coded dichotomously as "dominant culture" (for Canada, the USA and the UK, people who reported being white only and for Australia, people whose spoken language at home was English only) and "other" (for Canada, the USA and the UK, people who reported any other ethnic group and for Australia, people who spoke a language at home other than English).

\section{Statistical analysis}

The data were analysed using SPSS Version 12. Percentages reported in this paper were weighted for age and sex for each country using the longitudinal weights for Wave 1 continuers, as described in Thompson et al. ${ }^{13}$ However, all multivariate analyses were conducted on unweighted data. Bivariate analyses were conducted on both weighted and unweighted data and, where results differed, the lower significance level is reported.

The sampling design approximates stratified random sampling with proportional allocation in each country. Since there is no clustering in the design, any increase in standard errors from the sampling design would arise from the variability in the sampling weights, used to adjust for non-response and attrition. Since the sampling weights are calibrated to smoker prevalence numbers by sex and age group from national surveys, and since their coefficients of variation are not high (see Thompson et al, ${ }^{13}$ ) the increase in standard errors is very small, and does not affect the significance of the results reported here.

The general linear model (GLM) repeated measures procedure was used to test whether any change in the number of channels through which participants noticed tobacco marketing between Waves 1 and 2, differed by country. The following continuous demographic variables were controlled for in the analysis: age, the number of cigarettes smoked per day, and the number of previous quit attempts.

The McNemar non-parametric test for paired samples was used to test differences in awareness of specific marketing channels between Waves 1 and 2 .

The impact of the UK tobacco marketing regulations was measured by focusing on those marketing channels that were subject to a change in regulation between Waves 1 and 2. Not all of the new UK regulations had come into force at the time of Wave 2. The analyses, therefore, examined the following forms of tobacco marketing: billboard advertisements, newspapers/ magazines advertisements and promotions. Owing to the large number of promotional channels affected by the change in 
Table 3 Awareness of tobacco marketing in the past six months, at wave 1

\begin{tabular}{|c|c|c|c|c|c|c|c|c|}
\hline & \multicolumn{2}{|c|}{$\begin{array}{l}\text { Canada } \\
\text { Wave } 1\end{array}$} & \multicolumn{2}{|c|}{$\begin{array}{l}\text { USA } \\
\text { Wave } 1\end{array}$} & \multicolumn{2}{|c|}{$\begin{array}{l}\text { Australia } \\
\text { Wave } 1\end{array}$} & \multicolumn{2}{|c|}{$\begin{array}{l}\text { UK } \\
\text { Wave } 1\end{array}$} \\
\hline & $\%$ & $95 \% \mathrm{Cl}$ & $\%$ & $95 \% \mathrm{Cl}$ & $\%$ & $95 \% \mathrm{Cl}$ & $\%$ & $95 \% \mathrm{Cl}$ \\
\hline \multicolumn{9}{|l|}{ Advertisements } \\
\hline Noticed tob ads in store & 54 & (52 to 57$)$ & 90 & (88 to 91 ) & 55 & (53 to 57 ) & 70 & (68 to 72 ) \\
\hline Noticed tob ads on billboards & 27 & ( 25 to 29 ) & 52 & (50 to 55$)$ & 19 & (17 to 21 ) & 60 & 158 to 62 \\
\hline Noticed tob ads in newspapers/mags & 40 & (38 to 42 ) & 62 & (60 to 65$)$ & 16 & (14 to 17 ) & 51 & $(48$ to 53 \\
\hline Noticed tob ads on TV & 17 & (15 to 19$)$ & 15 & (13 to 17$)$ & 12 & (10 to 13 ) & 16 & (14 to 18 \\
\hline Noticed tob ads on radio & 4 & $(3$ to 4$)$ & 7 & $(6$ to 9$)$ & 3 & (2 to 3 ) & 2 & (1 to 3$)$ \\
\hline Noticed tob ads at movie & 3 & (2 to 4 ) & 4 & (3 to 5$)$ & 4 & (3 to 5$)$ & 6 & (5 to 7$)$ \\
\hline \multicolumn{9}{|l|}{ Sponsorship } \\
\hline Sports sponsorship & 54 & (52 to 57$)$ & 37 & (35 to 40 ) & 35 & (33 to 38 ) & 63 & 160 to 65 \\
\hline Arts sponsorship & 23 & (21 to 25 ) & 10 & (8 to 11 ) & 7 & $(6$ to 9$)$ & 3 & $(2$ to 4$)$ \\
\hline \multicolumn{9}{|l|}{ Promotions } \\
\hline Special price & 26 & (24 to 28 ) & 87 & (86 to 89 ) & 35 & (32 to 37 ) & 62 & $(60$ to 64$)$ \\
\hline Direct mail & 3 & (2 to 3$)$ & 49 & (46 to 51 ) & 1 & (1 to 2 ) & 18 & $(16$ to 19$)$ \\
\hline Signs & 29 & (27 to 31 ) & 51 & (48 to 53 ) & 27 & (25 to 29 ) & 35 & (33 to 37 ) \\
\hline Branded clothing & 11 & (10 to 13$)$ & 38 & (35 to 40 ) & 14 & (12 to 15$)$ & 19 & (17 to 21 ) \\
\hline Free samples & 2 & $(2$ to 3$)$ & 39 & (36 to 42 ) & 6 & (5 to 7$)$ & 14 & (12 to 15 \\
\hline Gift/discount & 3 & (2 to 4$)$ & 34 & (32 to 37 ) & 11 & (10 to 13 ) & 18 & $(16$ to 20$)$ \\
\hline Competition & 16 & $(15$ to 18$)$ & 18 & $(16$ to 20$)$ & 8 & (7 to 9) & 10 & $(9$ to 11$)$ \\
\hline Leaflet & 3 & $(2$ to 3$)$ & 15 & (13 to 17 ) & 3 & (2 to 4 ) & 18 & $(16$ to 19$)$ \\
\hline Email & 3 & (2 to 4 ) & 10 & (8 to 11 ) & 2 & (1 to 3 ) & 2 & $(2$ to 3$)$ \\
\hline Mobile phone promotion & 0 & $(0$ to 0$)$ & 1 & (1 to 2$)$ & 1 & $(0$ to 1$)$ & 1 & (0 to 1$)$ \\
\hline Website & 3 & (2 to 4 ) & 11 & (9 to 13 ) & 3 & (2 to 3 ) & 3 & (3 to 4$)$ \\
\hline
\end{tabular}

Base: all cohort respondents giving valid responses at Wave 1 and Wave 2. Base numbers for each country range as follows: Canada (1659 to 1674), USA (1331 to 1339), Australia (1835 to 1876), UK (1846 to 1865).

The data in this table are weighted for age and sex for each country using the longitudinal weights for Wave 1 continuers, as described in Thompson et al. ${ }^{13}$

regulations, the composite promotions variable, awareness of any form of tobacco promotion, was used in the analyses. In addition, we also analysed the impact of impending regulation on sponsorship, using the combined variable awareness of sports or arts sponsorship. This was used as a means of grouping together similar forms of marketing to make the analysis more concise. Furthermore, in the UK (the focus of our analysis), the arts sponsorship awareness was negligible and therefore there was no room for a reduction in awareness.

Logistic regression was used to test whether tobacco marketing awareness at Wave 2 varied by country. The logistic regression analyses controlled for the potentially confounding effects of the following variables: sex, age, education, ethnicity, income, number of cigarettes smoked per day, and whether participants had ever tried to quit smoking. A difference approach was used, whereby the difference in awareness between Wave 2 and Wave 1 was used as the dependent variable. Change in awareness was coded dichotomously as either a favourable change (that is, reduced awareness) or no change/an unfavourable change in awareness (for example, not being aware at Wave 1 to being aware at Wave 2). The effect of the tobacco marketing ban on smokers' awareness in the UK was examined through a contrast which tested whether the UK differed from the average of the other three countries. In the analysis of change in sponsorship awareness the contrast tested whether Canada and the UK differed from Australia and the USA, as bans on sponsorship were imminent in both Canada and the UK.

\section{RESULTS}

The results firstly address how participants in the four countries differed, at baseline and over time, in their awareness of tobacco marketing and how this related to the level of regulation in each country. Secondly the results address the impact of the UK ban on awareness, and thirdly whether the UK ban led to a shift to use of channels unaffected by the ban.

Table 4 Awareness of tobacco marketing, by country, at wave 2

\begin{tabular}{|c|c|c|c|c|c|c|c|c|}
\hline & \multicolumn{2}{|c|}{$\begin{array}{l}\text { Canada } \\
\text { Wave } 2\end{array}$} & \multicolumn{2}{|c|}{$\begin{array}{l}\text { USA } \\
\text { Wave } 2\end{array}$} & \multicolumn{2}{|c|}{$\begin{array}{l}\text { Australia } \\
\text { Wave } 2\end{array}$} & \multicolumn{2}{|c|}{$\begin{array}{l}\text { UK } \\
\text { Wave } 2\end{array}$} \\
\hline & $\%$ & $95 \% \mathrm{Cl}$ & $\%$ & $95 \% \mathrm{Cl}$ & $\%$ & $95 \% \mathrm{Cl}$ & $\%$ & $95 \% \mathrm{Cl}$ \\
\hline \multicolumn{9}{|l|}{ Advertisements } \\
\hline Noticed tob ads in store & 53 & $(50$ to 55$)$ & 89 & (88 to 91$)$ & 48 & $(45$ to 50$)$ & 62 & (60 to 64$)$ \\
\hline Noticed tob ads on billboards & 25 & (23 to 27 ) & 46 & (44 to 49 ) & 14 & (12 to 15$)$ & 35 & (33 to 37 ) \\
\hline Noticed tob ads in newspapers/mags & 37 & (35 to 39$)$ & 59 & (56 to 61$)$ & 14 & (12 to 15$)$ & 31 & (29 to 34$)$ \\
\hline \multicolumn{9}{|l|}{ Sponsorship } \\
\hline Sports sponsorship & 41 & (39 to 43 ) & 42 & (39 to 44$)$ & 33 & (31 to 35$)$ & 53 & $(51$ to 55$)$ \\
\hline Arts sponsorship & 16 & (14 to 18$)$ & 7 & (6 to 8$)$ & 3 & (3 to 4$)$ & 2 & (1 to 3 ) \\
\hline \multicolumn{9}{|l|}{ Promotions } \\
\hline Special price & 31 & (28 to 33$)$ & 80 & (78 to 82 ) & 29 & (27 to 31$)$ & 46 & (44 to 48 ) \\
\hline Direct mail & 2 & (1 to 2$)$ & 44 & (42 to 47$)$ & 0 & $(0$ to 1$)$ & 10 & (9 to 11$)$ \\
\hline Signs & 22 & (20 to 23 ) & 44 & $(41$ to 46$)$ & 19 & (17 to 21$)$ & 23 & (21 to 25 ) \\
\hline Branded clothing & 11 & (10 to 13 ) & 32 & (30 to 35$)$ & 11 & (10 to 12$)$ & 11 & (10 to 13$)$ \\
\hline Free samples & 2 & (1 to 2$)$ & 30 & (28 to 33 ) & 3 & (2 to 4 ) & 7 & (5 to 8$)$ \\
\hline Gift/discount & 4 & $(3$ to 5$)$ & 29 & (27 to 31$)$ & 10 & (9 to 12$)$ & 10 & $(9$ to 11$)$ \\
\hline
\end{tabular}

Base: all cohort respondents giving valid responses at Wave 1 and Wave 2. Base numbers for each country range as follows: Canada (1659 to 1674 ), USA (1331 to 1339), Australia (1835 to 1876), UK (1846 to 1865).

The data in this table are weighted for age and sex for each country using the longitudinal weights for Wave 1 continuers, as described in Thompson et al. ${ }^{13}$ 
Table 5 Awareness of tobacco marketing, by country: difference between wave 2 and wave 1 awareness

\begin{tabular}{|c|c|c|c|c|c|c|c|c|}
\hline & \multicolumn{2}{|c|}{$\begin{array}{l}\text { Canada } \\
\text { W2-W1 }\end{array}$} & \multicolumn{2}{|c|}{$\begin{array}{l}\text { USA } \\
\text { W2-W1 }\end{array}$} & \multicolumn{2}{|c|}{$\begin{array}{l}\text { Australia } \\
\text { W2-W1 }\end{array}$} & \multicolumn{2}{|c|}{$\begin{array}{l}\text { UK } \\
\text { W2-W1 }\end{array}$} \\
\hline & $\%$ & $95 \% \mathrm{Cl}$ & 5 & $95 \% \mathrm{Cl}$ & $\%$ & $95 \% \mathrm{Cl}$ & $\%$ & $95 \% \mathrm{Cl}$ \\
\hline \multicolumn{9}{|l|}{ Advertisements } \\
\hline Noticed tob ads in store & -2 & $(-3$ to -1$)$ & 0 & $(0$ to 0$)$ & $-8^{* \pm *}$ & $(-9$ to -6$)$ & $-8^{*+*}$ & $(-9$ to -7$)$ \\
\hline Noticed tob ads on billboards & -2 & $(-2$ to -1$)$ & $-6 * t$ & $(-7$ to -5$)$ & $-5^{*+*}$ & $(-6$ to -4$)$ & $-25^{* * *}$ & $(-27$ to -23$)$ \\
\hline Noticed tob ads in newspapers/mags & $-3^{*}$ & $(-4$ to -2$)$ & $-4^{*}$ & $(-5$ to -3$)$ & $-2^{*}$ & $(-3$ to -1$)$ & $-19^{*+*}$ & $(-21$ to -18$)$ \\
\hline \multicolumn{9}{|l|}{ Sponsorship } \\
\hline Sports sponsorship & $-13^{* * * *}$ & $(-15$ to -12$)$ & $5^{* *}$ & $(3$ to 6$)$ & -2 & $(-3$ to -1$)$ & $-9^{* * *}$ & $(-11$ to -8$)$ \\
\hline Arts sponsorship & $-7^{*+*}$ & $(-8$ to -6$)$ & $-3^{* *}$ & $(-3$ to -2$)$ & $-4^{+* *+}$ & $(-5$ to -3$)$ & -1 & $(-1$ to 0$)$ \\
\hline \multicolumn{9}{|l|}{ Promotions } \\
\hline Special price & $5^{* * *}$ & $(4$ to 6$)$ & $-8^{*+* t}$ & $(-9$ to -6$)$ & $-5^{+* *+}$ & $(-6$ to -4$)$ & $-16^{* * *}$ & $(-18$ to -15$)$ \\
\hline Direct mail & $-1^{*}$ & $(-1$ to -1$)$ & $-5^{\text {t*t* }}$ & $(-6$ to -3$)$ & -1 & $(-1$ to 0$)$ & $-8^{*+*+}$ & $(-9$ to -6$)$ \\
\hline Signs & $-8^{*+*}$ & $(-9$ to -6$)$ & $-7^{*+*}$ & $(-8$ to -5$)$ & $-8^{+* *+}$ & $(-9$ to -6$)$ & $-12^{* * *}$ & $(-13$ to -10$)$ \\
\hline Branded clothing & 0 & $(0$ to 0$)$ & $-6^{* *}$ & $(-7$ to -4$)$ & $-3^{* *}$ & $(-3$ to -2$)$ & $-8^{n+\infty}$ & $(-9$ to -6$)$ \\
\hline Free samples & -1 & $(-1$ to 0$)$ & $-9^{*+*}$ & $(-10$ to -7$)$ & $-3^{+*+*}$ & $(-3$ to -2$)$ & $-7^{*+*}$ & $(-8$ to -6$)$ \\
\hline Gift/discount & 1 & (1 to 2 ) & $-5^{*}$ & $(-6$ to -4$)$ & -1 & $(-2$ to -1$)$ & $-8^{n+*+*}$ & $(-9$ to -7$)$ \\
\hline
\end{tabular}

McNemar test used to compare equality of Wave 2 awareness with Wave 1 awareness.

Significant differences in awareness levels are indicated as follows: ${ }^{*} p<0.05 ;{ }^{* *} p<0.01 ;{ }^{* * *} p<0.001$.

Base: all cohort respondents giving valid responses at Wave 1 and Wave 2. Base numbers for each country range as follows: Canada (1659 to 1674), USA (1331 to 1339), Australia (1835 to 1876), UK (1846 to 1865).

The data in this table are weighted for age and sex for each country using the longitudinal weights for Wave 1 continuers, as described in Thompson. ${ }^{13}$

\section{Comparison of tobacco marketing awareness levels across countries}

Awareness at Wave 1

Table 3 shows awareness of tobacco marketing at Wave 1, for each of the main channels. In Australia, the country with the highest number of controlled channels at Wave 1, the extent of awareness and range of channels of awareness were lower than the other countries. The most salient form of tobacco marketing was advertisements in store (55\%). Awareness of other forms of tobacco advertising, such as billboards and newspapers/magazines, were lower than $20 \%$. More than a third (35\%) was aware of sports sponsorship, demonstrating the consequences of exemptions. Promotion awareness was limited, with special price being the most salient (35\%).

In Canada, the main sources of tobacco marketing awareness at Wave 1 were from advertisements in stores (54\%), and from sports sponsorship (54\%). Fewer smokers $(40 \%)$ were aware of adverts in the press and even less of billboard adverts (27\%). While arts sponsorship (23\%) was considerably less salient than sports sponsorship (54\%), awareness of arts sponsorship featured in Canada more so than in other countries. Promotions did not feature highly in Canada with signs (29\%) and special price $(26 \%)$ being the most salient, noticed by around a quarter.

In the UK, awareness of tobacco marketing was high across a range of channels at Wave 1 . Smokers reported the greatest awareness for advertisements in store $(70 \%)$, on billboards $(60 \%)$ and sponsorship of sport (63\%). Among promotions, highest awareness was observed for special price (62\%).

In the USA, high levels of awareness were reported across the range of channels. Particularly high awareness was observed for tobacco advertisements in stores (90\%) and special price $(87 \%)$. Promotional forms such as direct mail, branded clothing, free samples and gift/discount, though relatively low in other countries, had awareness in excess of $30 \%$ in the USA. Despite regulation, over half $(52 \%)$ had noticed tobacco marketing in the form of billboards and over a third $(38 \%)$ on branded clothing.

\section{Awareness at Wave 2}

Tables 4 and 5 display the main channels through which participants encountered tobacco marketing at Wave 2 and the difference between Wave 1 and Wave 2 awareness. Note that channels that failed to achieve a baseline awareness of at least $20 \%$ in any one country are not presented in tables 4 and
5. Overall, similar patterns of awareness were reported as at Wave 1, with declines in awareness levels most pronounced among UK smokers consistent with the ad ban.* A common pattern of channel awareness was discernable across the four countries: store advertisements had the highest awareness levels across all four countries and, with the exception of the USA, sports sponsorship had the second highest awareness. The USA had comparable awareness levels for sports sponsorship as the other countries, but higher levels of awareness for a number of other channels.

"Logistic regression analyses were conducted, within each country, to test whether having completed the survey before affected participants' Wave 2 responses about noticing in specific marketing channels and overall salience of pro-smoking cues. The cohort data were compared with those of the replenishment sample at Wave 2, which comprised a further 1714 adult smokers (517 in Canada, 684 in the USA, 258 in Australia and 255 in the UK). A sample variable was included as an additional covariate, which identified whether a respondent was part of the cohort who had completed surveys at both Waves 1 and 2 or from the replenishment sample who had only completed the Wave 2 survey. The influence of the sample variable was non-significant for all countries for the following variables: adverts on billboards, in newspapers/ magazines, on radio, at movies, arts sponsorship, special price, signs, branded clothing, free samples, gift/discount, promotional emails, mobile phone promotions, and websites.

In Canada, the USA and Australia, where there was no high profile intervention between Waves 1 and 2, the sample variable was significant for a selection of variables. The cohort participants in Canada were significantly less likely than replenishment participants to report noticing competitions (adjusted $\mathrm{OR} 0.618,95 \% \mathrm{Cl} 0.459$ to $0.832 ; p=0.001$ ), sports sponsorship (adjusted OR $0.561,95 \% \mathrm{Cl}$ 0.454 to $0.694 ; \mathrm{p}<0.001$ ) and overall pro-smoking cues (adjusted OR $0.743,95 \% \mathrm{Cl} 0.560$ to $0.985 ; \mathrm{p}=0.039$ ). Similarly cohort participants in the USA were significantly less likely than replenishment participants to report noticing tobacco adverts on TV (adjusted OR $0.697,95 \% \mathrm{Cl} 0.530$ to $0.917 ; \mathrm{p}=0.010$ ), and those in Australia were significantly less likely than replenishment participants to report noticing pro-smoking cues (adjusted OR $0.567,95 \% \mathrm{Cl} 0.384$ to 0.837 ; $\mathrm{p}=0.004$ ) and leatlets (adjusted OR $0.302,95 \% \mathrm{Cl} 0.121$ to 0.753 ; $p=0.010$ ). These findings are consistent with a time-in-sample effect in which awareness measures decline somewhat with time in sample, in the absence of change. However, in the UK, time-in-sample effects were significant in only two cases, and showed a different pattern: cohort participants were significantly more likely than replenishment participants to report noticing store advertisements (adjusted OR 1.398, 95\% $\mathrm{Cl} 1.063$ to $1.838 ; \mathrm{p}=0.017$ ), and direct mail promotions (adjusted OR $1.845,95 \% \mathrm{Cl} 1.804$ to $3.139 ; p=0.024)$.

These findings are consistent with interpreting the greater differences in awareness in the UK between Waves 1 and 2 as real trends, not artefacts of the repeated survey. 


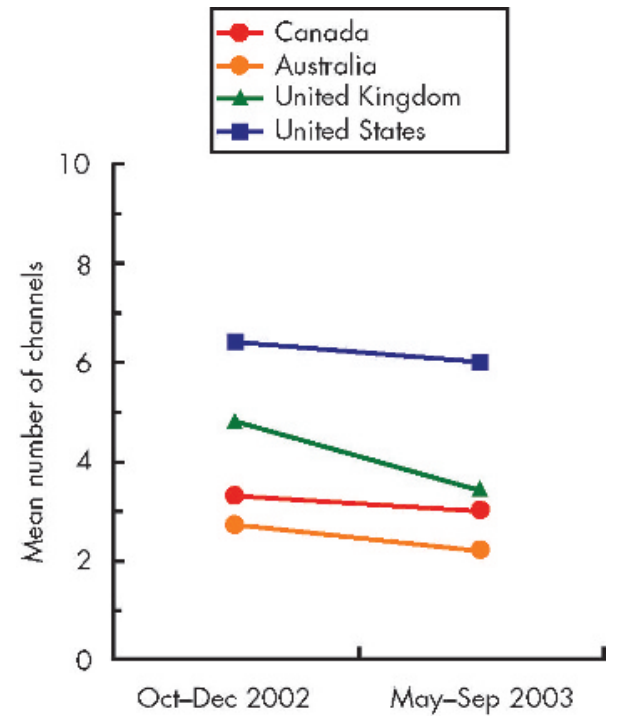

Figure 1 Average number of channels through which tobacco marketing was noticed at Wave 1 (October-December 2002) and Wave 2 (May-September 2003) by country.

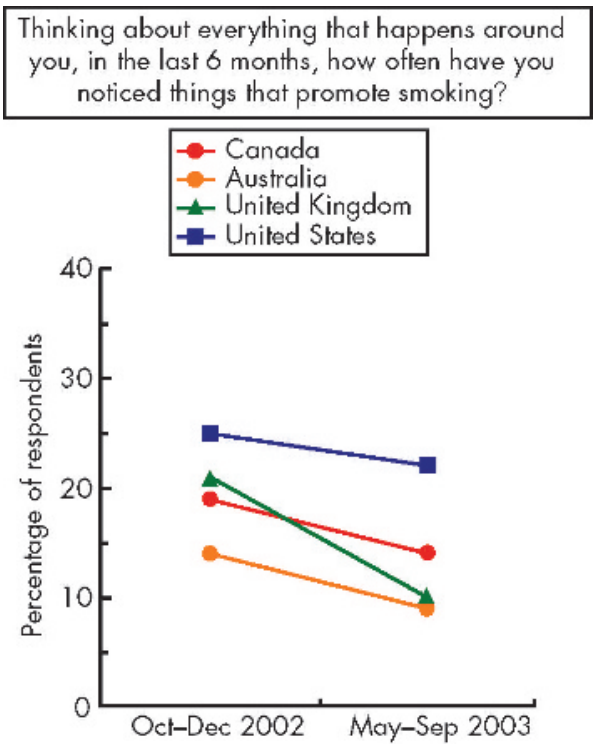

Figure 2 Percentage of respondents who noticed pro-smoking cues often or very often in the last six months at Wave 1 (October-December 2002) and Wave 2 (May-September 2003) by country.

Participants reported low levels of awareness (less than $20 \%$ ) at Wave 2 for: television ( $11-16 \%$ ); radio ( $1-7 \%$ ); movie (3-5\%); competition (4-17\%); promotional leaflet (1-14\%); promotional email (3-12\%); mobile phone promotion (0$1 \%)$; and promotional website (2-12\%).

\section{Association between marketing restrictions and overall awareness}

Overall awareness of tobacco marketing was examined by counting the total number of channels through which participants had noticed tobacco marketing. Awareness levels seemed to be consistent with the level of regulation. Australia, with the highest level of regulation, had lowest awareness and the USA, with a low level of regulation, had highest awareness (fig 1).

Furthermore, between Waves 1 and 2, following increased regulation in the UK, there was a steeper decline in the

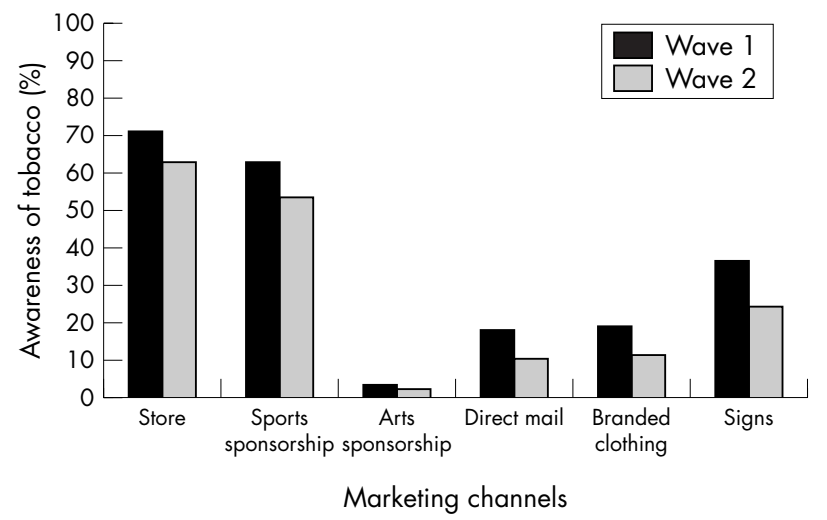

Figure 3 Awareness of the tobacco marketing channels remaining open in the UK.

overall awareness in the UK relative to the other countries. GLM repeated measures analyses showed a significant effect of survey wave by country for the number of channels where tobacco marketing was noticed $(\mathrm{F}(3,5352)=58.168$, $\mathrm{p}<0.001)$.

\section{Impact of UK ban}

Impact of the UK ban was examined in terms of impact on (1) overall awareness; (2) awareness of specific channels banned between Waves 1 and 2; and (3) awareness of channels remaining open in the UK.

\section{Impact of UK ban on overall awareness of tobacco marketing}

Figure 2 shows a decline between Waves 1 and 2, in the salience of pro-smoking cues (the proportion who "often" or "very often" noticed things that promote smoking). This decline was more pronounced in the UK where salience of pro smoking cues were 1.5 times more likely to decline among UK smokers than in the other three countries (adjusted odds ratio (OR) 1.509, 95\% confidence interval (CI) 1.290 to 1.766; $\mathrm{p}<0.001$ ). Nevertheless, as fig 2 shows, $9-22 \%$ of smokers in the four countries still reported noticing things that promoted smoking "often or very often" at Wave 2 .

Impact of UK ban on awareness of specific channels We also examined changes in noticing marketing among UK smokers, relative to changes among smokers from the other countries for channels that were banned in the UK between Waves 1 and 2: billboards; newspaper/magazine adverts; and any type of promotion. (Note that awareness of radio advertisements was not analysed because the low incidence of radio advertisements at Wave 1 -only $2 \%$ in the UKmeant that there was little room for change at Wave 2.) For each of the newly controlled channels, UK smokers were significantly more likely to report declines in noticing at Wave 2, relative to smokers in the other three countries. Smokers in the UK were more likely to report a decline in noticing adverts on billboards at Wave 2 (adjusted OR 2.724, 95\% CI 2.381 to $3.117 ; \mathrm{p}<0.001$ ), adverts in newspapers/ magazines (adjusted OR 2.351, 95\% CI 2.046 to 2.702; $\mathrm{p}<0.001$ ) and any promotions (adjusted OR 2.317, 95\% CI 1.996 to $2.689 ; \mathrm{p}<0.001)$. We also examined another channel, sponsorship, for which a ban was imminent in the UK and Canada. This was a post-hoc analysis conducted to supplement the focal research questions relating to the implemented UK advertising ban. It showed there was also a decline in awareness of tobacco sponsorship in the countries where a ban was imminent, Canada and the UK, relative to 
Australia and the USA where regulation was unchanged (adjusted OR 1.742, 95\% CI 1.521 to 1.997 ; p < 0.001).

\section{Awareness of the tobacco marketing channels remaining open in the UK}

Figure 3 shows changes in the levels of awareness among UK smokers for marketing channels that remained unrestricted at Wave 2 (that is, they were not covered in the ban or had not yet come into force). For each channel a small but significant decrease in awareness was observed in the UK (table 3). The uncontrolled channel with the highest awareness levels at both Wave 1 and Wave 2 was store ( $70 \%$ and $62 \%$, respectively). Store advertising was also the channel where a window of opportunity existed for increased marketing effort owing to the delay in regulations being introduced because the industry had appealed against the control of this channel. Yet even here awareness levels declined between the two waves. Given this decline there is no evidence of there being increased use of marketing channels by the tobacco industry that remained "open" in the UK.

\section{DISCUSSION}

Levels of smokers' awareness of tobacco promotion were consistent with the level of advertising and promotion regulation in each country at each survey wave. For example, awareness levels were noticeably higher in the USA, where there are fewer controls than in the other countries. In this sense, this study provides evidence that advertising regulations work in a dose dependent manner-the more comprehensive the ban the lower the exposure to tobacco marketing influences.

The results of the UK ban provide further confirmation of the benefits of a comprehensive advertising ban and demonstrate the likely mechanism by which it affects consumption. ${ }^{3}$ This study showed that a comprehensive advertising ban reduced smokers' exposure to tobacco advertising, meaning that there are less salient cues around to stimulate smoking. In the UK, smokers reported a decline in exposure to pro-tobacco marketing after the ban went into effect. The decline in exposure to pro-tobacco marketing was greater in the UK compared with the other three countries that did not implement new regulation. The reported decline in exposure to tobacco marketing through the channels impacted by the regulation provides further evidence to demonstrate the impact of the regulation. The decline in awareness of sports or arts sponsorship in the UK and Canada in the face of imminent regulation of tobacco sponsorship is probably a result of a decline in promotion of sponsorships as the number declines close to the formal date, with contracts not being renewed or extended. That we found a similar decline in sponsorship awareness in these two countries demonstrates convergent validity, in addition to the discriminant validity shown by the above findings. Thus this demonstrates the power of the ITC Project measures and design to detect both change and stasis in regulation.

At least in the short term it appears that the UK ban did not result in notable increases in exposure to tobacco product marketing in channels not affected by the regulation as might be expected from past work. ${ }^{14}$ It should be noted, however, that Wave 2 took place only months after the ban was implemented, and it is possible that compensatory activity might occur in future. Subsequent waves of ITC-4 will allow us to monitor the shifting of salience, if it occurs over time.

The UK legislation prohibits all tobacco marketing whose "purpose" or "effect" is to promote tobacco. Its intent is thus very clear and its effect is comprehensive. ${ }^{3}$ Exceptions to the UK ban were temporary (for example, regulation of

\section{What this paper adds}

Research has shown that tobacco advertising increases tobacco consumption. Policymakers have responded to the public health threat posed by tobacco marketing by introducing regulatory policies to control the industry's advertising and promotional activities, and the Framework Convention on Tobacco Control calls for comprehensive bans on such activities. Saffer and Chaloupka concluded that comprehensive bans can reduce tobacco consumption, but partial bans have little or no effect. This paper reports the results of the first-ever evaluation of a comprehensive national ban on tobacco advertising and promotion, which took place in the United Kingdom in February 2003, compared to three countries-Australia, Canada, and the United States.

The data show that increased regulation of tobacco promotion leads to significant declines in awareness of the controlled channels and a decline in the overall prevalence of pro smoking cues. The comprehensive UK ban on tobacco promotion appears to have been successfully implemented; there was no evidence that the tobacco industry was able to undermine it by increasing their promotional activity in the few remaining channels. These findings reinforce the importance of comprehensive bans on tobacco advertising and promotion. Nevertheless, notable levels of pro smoking cues remained across all four countries, including the UK, suggesting that, while necessary, regulations are not sufficient and that residual pro smoking cues arise from the very presence of a legitimate tobacco market.

sponsorship and store advertisements did not come into immediate effect) or minor (for example, direct mail is only permissible where prior permission from the addressee has been obtained to send material). The findings suggest the UK legislation joins that of Australia as a model of good practice.

Despite regulation, however, high levels of pro smoking cues remained across all four countries, including the UK. In the UK, this may partially be a result of residual promotional awareness: respondents were asked about noticing advertising and promotions in the last six months, whereas in some cases the UK restrictions had only been introduced for two to three months. We would expect to see further reductions in awareness in the next survey wave. However, even in Australia, where the ban on promotional channels has been in place for a long time, notable levels of pro smoking cues were reported. This might be explained by a mixture of promotion in channels where promotion is still allowed (point of sale, on packaging, and sponsorship exemptions), incidental promotions (for example, in movies) and through cross-border advertising (either direct via satellite TV or the internet, or indirectly-for example, broadcast of sporting events like Grand Prix with lots of promotion on cars and around the track). The substantial awareness of sports sponsorship where exemptions are allowed (for example, Formula One racing) demonstrates the importance of not allowing such exemptions.

These findings suggest that, even when direct, labelled tobacco company promotional activity is comprehensively and effectively removed, many messages in favour of smoking remain through-for example, point of sale, incidental advertising in movies and from the pack itself. We would argue that these are an inevitable side effect of a legitimate market for tobacco, which involves companies not just in promotional activity but product development, packaging, distribution, pricing, and indirect forms of 
advertising, such as buzz or lifestyle advertising, as has been reported from Australia, all designed to maximise their share of the market. ${ }^{15}$ To further strengthen advertising bans key areas to address include cigarette packaging, where cigarettes are permitted for sale and price marketing. In the USA, a lot of innovation in pack design followed the Tobacco Master Settlement Agreement. Packaging is especially important in countries with comprehensive advertising bans, where advertising is largely restricted to point of purchase, as demonstrated by industry documents. ${ }^{16}$ Again in the USA, much of the $\$ 15$ billion spent on cigarette marketing in 2003 was spent on discounting incentives to retailers and consumers. Generic packaging and selling all cigarettes for a fixed "high" price would help to strengthen the regulation of tobacco marketing.

\section{CONCLUSIONS}

Our findings reinforce the importance of comprehensive bans on tobacco advertising and promotion, which is called for under the FCTC. This study demonstrates that a comprehensive ban does reduce exposure to product marketing, although not completely, because of the residual advertising. This finding helps to explain why Saffer and Chaloupka found that comprehensive advertising bans reduce cigarette consumption and suggests that governments need to monitor exposure to product marketing as an intermediate marker in the success of an advertising ban policy. ${ }^{3}$

\section{ACKNOWLEDGEMENTS}

The research was funded by grants from the US National Cancer Institute/NIH (from the Roswell Park Transdisciplinary Tobacco Use Research Center (TTURC), P50 CAl11236, and from R01 CAl00362), the Canadian Institutes for Health Research (57897), Robert Wood Johnson Foundation (045734), the Australian National Health and Medical Research Council (265903), Cancer Research UK (C312/ A3726), the Australian Commonwealth Department of Health and Ageing, the Centre for Behavioural Research and Program Evaluation of the National Cancer Institute of Canada/Canadian Cancer Society, and the Canadian Tobacco Control Research Initiative.

\section{Authors' affiliations}

F Harris, The Open University, Milton Keynes, UK

A M MacKintosh, S Anderson, G Hastings, University of Stirling, Stirling, UK

R Borland, The Cancer Council Victoria, Carlton, Victoria, Australia
G T Fong, D Hammond, University of Waterloo, Waterloo, Ontario, Canada

K M Cummings, Roswell Park Cancer Institute, Buffalo, New York, USA

Competing interest statement: There are no competing interests to declare.

Ethics approval: The study protocol was cleared for ethics by the Institutional Review Boards or Research Ethics Boards in each of the countries: the University of Waterloo (Canada), Roswell Park Cancer Institute (USA), the University of Illinois-Chicago (USA), the University of Strathclyde (UK), and The Cancer Council Victoria (Australia).

\section{REFERENCES}

1 Economics, Operational Research Division. (EORD), Department of Health (UK) Effect of tobacco advertising on tobacco sponsorship: a discussion document reviewing the evidence. London: Department of Health, 1992, (Smee report).

2 United Kingdom Department of Health Social Security. (UKDHHS) Effect of tobacco advertising on tobacco consumption. London: HMSO, 1992.

3 Saffer H, Chaloupka F. The effect of tobacco advertising on tobacco consumption. J of Health Econ 2000;19:1117-37.

4 MacFadyen L, Hastings G, MacKintosh A. Cross sectional study of young people's awareness of and involvement with tobacco marketing. BMJ 2001;322:513-7.

5 Aitken PP, Eadie DR, Hastings GB, et al. Predisposing effects of cigarette advertising on children's intentions to smoke when older. Br J Addiction $1991 ; 86: 383-90$

6 Framework Convention on Tobacco Control (FCTC). The Framework Convention on Tobacco Control Treaty 2004. http, // http://www.fctc.org/ about_FCTC/ (Accessed 25 Apr 2005).

7 HMSO. The Tobacco Advertising and Promotion Act 2002. http:// www.hmso.gov.uk/acts/acts2002/20020036.htm (Accessed 24 Mar 2005).

8 World Health Organisation Regional Office for Europe. Warsaw Declaration for a Tobacco-free Europe 2002. http://www.euro.who.int/aboutwho/ policy/20020422_1 (Accessed 4 May 2005).

9 Australian Government Department of Health and Aging. 2005. http:// www.health.gov.au/internet/wcms/publishing.nsf/Content/health-pubhlthstrateg-drugs-tobacco-act_review.htm (Accessed 11 Apr 2005).

10 Health Canada. The Tobacco Act. 2005. http://www.hc-sc.gc.ca/hecs-sesc/ tobacco/legislation/tobacco_act.html (Accessed 4 May 2005)

11 ASHUK. ASH briefing: The UK ban on tobacco advertising. 2005. http:// www.ash.org.uk/html/advspo/html/timetable.html (Accessed 21 Feb 2005)

12 Office of the Attorney General. Tobacco Master Settlement Agreement. 2005. http://ag.ca.gov/tobacco/resources/msasumm.htm (Accessed 2 Mar 2005).

13 Thompson ME, Fong GT, Hammond D, et al. Methods of the International Tobacco Control (ITC) Four Country Survey. Tob Control 2006; 15(suppl III):iii 12-18.

14 Laugesen M, Meads C. Tobacco advertising restrictions, price, income, and tobacco consumption in OECD countries 1960-1986. J Addict 1991;86:1343-54.

15 Harper T. Marketing life after advertising bans. Tob Control 2001;10:196-8.

16 Wakefield M, Morley C, Horan JK, et al. The cigarette pack as image: new evidence from tobacco industry documents. Tob Control 2002;11(suppl I):i73-80. 